\title{
Theoretical Study on Spin-Forbidden Transitions of Osmium Complexes by Two-component Relativistic Time-dependent Density Functional Theory
}

\author{
Yutaka Imamura, ${ }^{a}$ Muneaki Kamiya, a,b Takahito Nakajima ${ }^{\mathrm{a},}{ }^{,}$ \\ ${ }^{a}$ RIKEN, Advanced Institute for Computational Science, 7-1-26, Minatojima-minami-machi, Chuo-ku, Kobe, \\ Hyogo, 650-0047, Japan \\ ${ }^{\mathrm{b}}$ Studies in Regional Environment, Department of Policy Studies, Faculty of Regional Studies, Gifu \\ University, 1-1, Yanagido, Gifu, Gifu, 501-1193, Japan
}

*Corresponding author, FAX +81-78-304-4962

E-mail address: nakajima@riken.jp, Takahito Nakajima 


\begin{abstract}
We study spin-forbidden transitions of Os polypyridyl sensitizers by two-component relativistic time-dependent density functional theory with the spin-orbit interaction based on Tamm-Dancoff approximation. The absorption spectra, including spin-forbidden-transition peaks, for the Os complexes are reasonably reproduced in comparison with the experimental ones. The extension of the conjugated lengths in the Os complexes is investigated and found to be effective to enhance photo absorption for spin-allowed transitions as well as spin-forbidden ones. This study provides fruitful information for a design of new dyes in terms of conjugation lengths.
\end{abstract}




\section{Introduction}

The extension of absorption spectra of dye sensitizers to longer wavelength is an urgent mission for the dye-sensitized solar cell (DSSC), which is expected as a promising renewable energy source. Many attempts to widen absorption spectra for dye sensitizers have been carried out so far in order to exceed $11 \%$ to $12 \%$ energy conversion efficiency [1-5]. In spite of extensive efforts for developing new dyes, no rapid or significant increase in the energy conversion efficiency has been achieved. A new approach has been demanded for realizing a practical energy conversion efficiency, $15 \%$.

Recently, the enhancement of incident photon-to-current efficiency (IPCE) via spin forbidden transitions has been explored. A phosphine-coordinated Ru(II) sensitizer, (DX1) dye [6] designed to have strong spin-forbidden transitions has recorded the highest photocurrent density as a DSSC. In addition to the Ru complex, Os complexes with spin-forbidden transitions have also been reported. The heavy element Os intrinsically exhibits a strong spin-orbit interaction and is advantageous over lighter elements including $\mathrm{Ru}$ in terms of the spin-forbidden transitions. The extension of the conjugation length in the ligand was reported to be effective for the IPCE enhancement for the Os complexes: [Os(tcterpy)-(4,4'-bis(p-butoxystyryl)-2,2'-bipyridine)Cl] $\mathrm{PF}_{6}$ (Os-stbpy) with a long conjugation length is more efficient than $\left[\mathrm{Os}\left(\right.\right.$ tcterpy)(tbbpy)Cl] $\mathrm{PF}_{6}$ (Os-tbbpy) [7]. The detailed information regarding the IPCE enhancement of the Os complexes have not been investigated so far.

In order to design efficient dye sensitizers, we investigate the Os complexes with the strong spin-forbidden transitions using two-component relativistic time-dependent density functional theory (2c-TDDFT) with the spin-orbit interaction based on Tamm-Dancoff approximation (TDA) [8-10], which our group has recently developed into NTChem [11]. Our previous study on the DX1 and DX1 derivatives [12] and other researches [13-15] assure that the 2c-TDDFT with the spin-orbit interaction could describe spin-forbidden transitions with a reasonable cost and accuracy. We first 
examine spin-forbidden transitions for the Os-stbpy and Os-tbbpy complexes, in comparison to experimental results, and next evaluate the impact of absorption spectra from the extension of the conjugation lengths of the aromatic ligands using Os polypyridyl models. 


\section{Computational details}

All electronic calculations for excited states were carried out by 2c-TDDFT/TDA with the spin-free and spin-dependent parts of third [16] and first order [17] Douglas-Kroll (DK) Hamiltonians, respectively, which was implemented into NTChem [11]. The screened nucleus spin-orbit approximation was adopted for the spin-dependent part [18]. The basis sets used were Sapporo-DK-DZP for Ru and Os [19] and cc-pVDZ-DK [20] for the other atoms. The PBE1PBE functional [21] was adopted for 2c-TDDFT/TDA. The geometries of all complexes were optimized using the DL-FIND program [22] by the scalar-relativistic DFT with PBE1PBE. The oscillator strengths were estimated according to the formulation of Ref. [23]. 


\section{Results and discussion}

We first report absorption spectra of the Os complexes such as Os-stbpy and Os-tbbpy as shown in Figure 1. Next, we examine the roles of the metal and conjugation lengths of aromatic ligands using Os complex models.

\subsection{Absorption spectra of Os complexes}

We discuss the orbitals for the Os-tbbpy and Os-stbpy complexes. The formal charges of Os-tbbpy and Os-stbpy are +1 , and tetrabutylammonium in the Os-stbpy complex is replaced by hydrogen atoms. Table 1 lists the orbital energies calculated by 2c-relativistic DFTs with and without the spin-orbit interaction. In the TDDFT calculation, the effect of 188 and 193 methanol solvents for the Os-tbbpy and Os-stbpy complexes was considered by the point charges, which were determined by the Merz-Singh-Kollman scheme $[24,25]$ in the preliminary calculation of a methanol molecule. The geometries of the solvents were optimized by the molecular mechanics (MM) calculation with OPLSaa potentials [26] using TINKER [27] for the fixed geometries of the dyes [28] with the point charges determined by the Merz-Singh-Kollman scheme. Since the Os-stbpy and Os-tbbpy complexes have a quasi-octahedral symmetry, five $d$ orbitals are categorized as $t_{2 g}$ - and eg-type groups for the scalar relativistic DFT calculations: The highest occupied molecular orbital (HOMO), HOMO-1, and HOMO-2 belong to the $t_{2 \mathrm{~g}}$-type orbitals and the low-lying unoccupied MOs are distributed over the aromatic ligands. The spin-orbit interaction leads to the orbital energy differences in the $t_{2 g}$-type orbitals because of the nature of $d$ orbitals. On the other hand, the lowest unoccupied molecular orbital (LUMO) and LUMO+1 are significantly less affected by the spin-orbit interaction. This behavior is basically consistent with the previous analysis [12]. The HOMO-LUMO gap for the Os-tbbpy complex is estimated to be 2.74 and $2.59 \mathrm{eV}$ for the relativistic DFT calculations without and with the spin-orbit interaction, whereas those for the Os-stbpy complex are estimated to be lower: 2.60 and $2.48 \mathrm{eV}$, respectively. Therefore, the Os-stbpy is expected to be a good candidate for long-wavelength absorption since the low-lying excited states for the Os 
complexes, to be discussed later, mainly involve $t_{2 \mathrm{~g}}$ - and $\pi^{*}$-type orbitals.

We investigate the low-lying transitions for the Os complexes through the 2c-TDDFT/TDA methodology, which is an effective tool for the spin-forbidden transition [12-15]. The numerical data and absorption spectra are shown in Table 2 and Figure 2, respectively. The experimental data are taken from Ref. [7]. For the Os-tbbpy complex, the first and second lowest triply degenerate singlet-triplet transitions from HOMO and HOMO-1 to LUMO appear at 1.35 and $1.40 \mathrm{eV}$ for 2c-TDDFT/TDA without the spin-orbit interaction. The spin-orbit interaction splits them into six transition energies: $1.17,1.18,1.27,1.32,1.57$, and $1.57 \mathrm{eV}$, respectively. The third and fourth lowest transitions have relatively large oscillator strengths of 0.0113 and 0.0030 . The seventh lowest transition with the oscillator strength 0.0188 is assigned to $\mathrm{H}-1->\mathrm{L}$.

For the Os-stbpy complex, 2c-TDDFT/TDA without the spin-orbit interaction similarly estimates the first and second lowest triply degenerate singlet-triplet transitions from HOMO and HOMO-1 to LUMO as 1.27 and $1.39 \mathrm{eV}$ lower than those for the Os-tbbpy complex, reflecting the HOMO-LUMO gap mentioned in the previous section. As seen in Os-tbbpy, the spin-orbit interaction generates six non-degenerate excited states of which the third and fourth lowest transitions at 1.19 and $1.27 \mathrm{eV}$ have the oscillator strengths of 0.0066 and 0.0108 . The seventh lowest transition energy with the oscillator strength 0.0161 is $1.68 \mathrm{eV}$.

We compare experimental and simulated absorption spectra. Figure 2 shows (a) experimental spectra of both Os complexes [7], (b) simulated ones of Os-tbbpy with/without the spin-orbit interaction, and (c) simulated ones of Os-stbpy with/without the spin-orbit interaction, respectively. Although the simulated spectra are slightly blue-shifted, probably because of the choice of an exchange-correlation functional, the general shapes of the spectra are, however, similar to the corresponding experimental ones. The experimental broad peaks around $900 \mathrm{~nm}$ for Os-tbbpy and Os-stbpy can be assigned to the spin-forbidden transitions; in more details, theoretical results indicate that the broad peak for Os-tbbpy mainly originates in the fourth lowest transition at $1.27 \mathrm{eV}$ 
with the oscillator strength 0.0113 , and the contribution from the third lowest transition seems relatively small in the absorption spectra. On the other hand, the broad peak for Os-stbpy consists of two peaks corresponding to the third and fourth lowest transitions at 1.19 and $1.27 \mathrm{eV}$ with the oscillator strengths of 0.0066 and 0.0108 , as easily confirmed for the simulated spectra. The two comparable peaks assigned to spin-forbidden transitions in the longer wavelength region for Os-stbpy effectively enhance the long wavelength absorption in comparison with Os-tbbpy. The experimental peaks around $650 \mathrm{~nm}$ are predicted to correspond to the seventh lowest transitions at 711 and $738 \mathrm{~nm}$ for Os-tbbpy and Os-stbpy, respectively. In the wavelengths ranging 400-600 nm, more peaks are observed for Os-stbpy than those for Os-tbbpy because Os-stbpy has more $\pi$ electrons than Os-tbbpy and, as a result, more transitions occur.

\subsection{Exploration of new dyes}

\subsubsection{Metal}

In order to explore new dyes, we investigate the modified complexes of Os-stbpy and Os-tbbpy, where Os is replaced with Ru. For simplicity, all calculations were performed without the solvent effect. The absorption spectra are shown in Figure 3. In Table 3, three lowest triply degenerate singlet-triplet transition and one lowest singlet-singlet transition for 2c-TDDFT/TDA without the spin-orbit interaction, and ten lowest excited states for 2c-TDDFT/TDA with the spin-orbit interaction are listed. For comparison, the corresponding data of Os-tbbpy and Os-stbpy are also shown in Figure 3 and Table 3. It is noted that the excitation energies for Os-tbbpy and Os-stbpy are slightly shifted due to the lack of the solvent effect, compared to those with solvents. The corresponding absorption spectra in wavenumber units are also available in the supplemental material.

For 2c-TDDFT/TDA without the spin-orbit interaction, all excitation energies of Ru-tbbpy and Ru-stbpy are higher than the corresponding ones of Os-tbbpy and Os-stbpy by at least $0.09 \mathrm{eV}$. For instance, the lowest singlet-triplet excitation energies of Os-tbbpy and Os-stbpy are 1.44 and 
$1.37 \mathrm{eV}$, whereas those for Ru-tbbpy and Ru-stbpy are 1.63 and $1.54 \mathrm{eV}$. Let us think about the effect of the spin-orbit interaction. For 2c-TDDFT/TDA with the spin-orbit interaction, the third and fourth lowest excited states for the $\mathrm{Ru}$ - and Os complexes assigned to spin-forbidden transitions are located in the range of $1.53-1.62$ and $1.28-1.40 \mathrm{eV}$, respectively. The corresponding oscillator strengths for the $\mathrm{Ru}$ complexes are smaller than those of the Os complexes. Therefore, the Os-tbbpy and Os-stbpy complexes are superior to Ru-tbbpy and Ru-stbpy regarding long-wavelength absorption via spin-forbidden transitions. This result is consistent with previous studies [12, 29].

As shown in Figure 3, the general shapes of the absorption spectra for the Ru complexes are similar to those of the Os complexes, which reflect the fact that the main excitations for the Ru complexes are not significantly changed by the replacement of the metal. As discussed above, the peaks assigned to the spin-forbidden transition for the Ru complexes are blue-shifted in comparison with the Os complexes. Stronger amplitudes of the absorption peaks, packed in the relatively narrow and short wavelength energy range for the $\mathrm{Ru}$ complexes, is advantageous for a high voltage, whereas less long wavelength absorption is not a good feature for a high electric current.

\subsubsection{Conjugation length}

In order to examine the effect of the conjugation lengths upon the absorption spectra in more detail, we estimate excitation energies of theoretically designed Os complexes (Os-stbpy-ext1 and Os-stbpy-ext2) with longer conjugation lengths of the planar ligand consisting of the $\mathrm{CH}=\mathrm{CH}-\mathrm{Ph}$ unit, as shown in Figure 4. All calculations were performed without the solvent effect.

First, we discuss the excitation energies calculated by 2c-TDDFT/TDA without the spin-orbit interaction. The numerical data are given in Table 3. The first lowest triply degenerate singlet-triplet transition for Os-tbbpy and Os-stbpy is assigned to the HOMO -> LUMO transition, whereas that for Os-stbpy-ext1 and Os-stbpy-ext2 is assigned to HOMO-2 -> LUMO transition. This difference is ascribable to the fact that HOMO and HOMO-1 for Os-stbpy-ext1 and Os-stbpy-ext2 are mainly composed of $\pi$-type orbitals distributed over aromatic ligands, and HOMO-2 has more 
nature of a $t_{2 g}$-type orbital. The first lowest triply degenerate singlet-triplet transition energies for the Os complexes are $1.37-1.44 \mathrm{eV}$ for $2 \mathrm{c}-\mathrm{TDDFT} / \mathrm{TDA}$ without the spin-orbit interaction. The first and second lowest triply degenerate singlet-triplet transition energies are unexpectedly not lowered by the elongation of the conjugation lengths of the Os complexes. However, the third lowest triply degenerate singlet-triplet transition energies are lowered: 1.92, 1.73, 1.67, and $1.53 \mathrm{eV}$ for Os-tbbpy, Os-stbpy, Os-stbpy-ext1, and Os-stbpy-ext2. The first lowest singlet-singlet transition energies non-linearly vary from 1.71 to $1.61 \mathrm{eV}$ with respect to conjugation lengths.

Figure 3 (c) illustrates the absorption spectra for Os-stbpy-ext1 and Os-stbpy-ext2 calculated by 2c-TDDFT/TDA with the spin-orbit interaction. The conspicuous difference is observed for the oscillator strengths of the first peak: the oscillator strengths of the third lowest transition in the order of Os-tbbpy, Os-stbpy, Os-stbpy-ext1, and Os-stbpy-ext2, are given as 0.0104, 0.0114, 0.00114, and 0.0113, whereas those of the fourth lowest transition are $0.0038,0.0067,0.0097$, and 0.0135 . The enhancement of the first peak with respect to the conjugation lengths is ascribed to the change of oscillator strengths of the fourth lowest state, which is induced by the elongation of the conjugation lengths. Also, the absorption spectra is widely enhanced in the energy range larger than $1.5 \mathrm{eV}$. Therefore, the numerical assessment on the Os complex models such as Os-stbpy-ext1 and Os-stbpy-ext2 reveals that the elongation of the conjugation lengths is an important factor for achieving a high IPCE for spin-allowed as well as spin-forbidden transitions. 


\section{Conclusions}

The present study has reported the spin-forbidden transitions for Os-stbpy and Os-tbbpy by 2c-TDDFT/TDA, which was implemented into the quantum chemistry program package, NTChem. We have demonstrated by the Os-complex models that the extension of a conjugation length effectively enhances oscillator strengths via spin-forbidden and spin-allowed transitions. The conjugation length would be a key factor for developing new dyes. However, electron injection from dyes to oxide semiconductor should be carefully designed for practical applications, because electron delocalization in dyes with a long conjugation length inhibits the interaction of the dyes with oxide semiconductor and may lead to poor electron injection. This investigation has thus provided useful information for construction of new sensitizers. 


\section{Acknowledgements}

The present study has been supported in part by competitive funding for team-based basic researches of 'Creation of Innovative Functions of Intelligent Materials on the Basis of the Element Strategy' from CREST, Japan Science and Technology (JST) Agency; FOCUS Establishing Supercomputing Center of Excellence; Grant-in-Aid for Scientific Research (C) 'KAKENHI 24550034' and Grant-in-Aid for Scientific Research on Innovative Areas 'KAKENHI 25104723'

from the Ministry of Education, Culture, Sports, Science and Technology (MEXT), Japan. 


\section{References}

[1] B. O’Regan, M. Grätzel, Nature 353 (1991) 737.

[2] M. K. Nazeeruddin , A. Kay, I. Rodicio , R. Humphry-Baker, E. Mueller, P. Liska , N. Vlachopoulos , M. Grätzel, J. Am. Chem. Soc. 115 (1993) 6382.

[3] M. K. Nazeeruddin, F. De Angelis, S. Fantacci, A. Selloni, G. Viscardi, P. Liska, S. Ito, B. Takeru, M. Grätzel, J. Am. Chem. Soc. 127 (2005) 16835.

[4] M. K. Nazeeruddin, P. Pechy, M. Grätzel, Chem. Commun. (1997) 1705.

[5] A. Yella, H. W. Lee, H. N. Tsao, C. Yi, A. K. Chandiran, M. K. Nazeeruddin, E. W. G. Diau, C. Y. Yeh, S. M. Zakeeruddin, M. Grätzel, Science 334 (2011) 629.

[6] T. Kinoshita, J. Ting Dy, S. Uchida, T. Kubo, H. Segawa, Nat. Photonics 7 (2013) 535.

[7] T. Kinoshita, J. Fujisawa, J. Nakazaki, S. Uchida, T. Kubo, H. Segawa. J. Phys. Chem. Lett. 3 (2012) 394 .

[8] E. Runge, E. K. U. Gross, Phys. Rev. Lett. 52 (1985) 997.

[9] F. Wang, T. Ziegler, J. Chem. Phys. Chem. Phys. 121 (2004) 12191.

[10] R. Bast, H. J. Aa. Jensen, T. Saue, Int. J. Quant. Chem. 109 (2009) 2091.

[11] NTChem 2013. http://labs.aics.riken.jp/nakajimat top/ntchem_e.html; T. Nakajima, M. Katouda, M. Kamiya, Y. Nakatsuka, Int. J. Quantum Chem. 115 (2015) 349.

[12] Y. Imamura, M. Kamiya, T. Nakajima, Chem. Phys. Lett. 635 (2015) 152.

[13] S. Fantacci, E. Ronca, F. De Angelis, J. Phys. Chem. Lett. 5 (2014) 375.

[14] E. Ronca, F. De Angelis, S. Fantacci, J. Phys. Chem. C,118 (2014) 17067.

[15] K. Mishima, T. Kinoshita, M. Hayashi, R. Jono, H. Segawa, K. Yamashita, S. H. Lin, Phys. Chem. Chem. Phys. 17 (2015) 12317.

[16] T. Nakajima, K. Hirao, J. Chem. Phys. 113 (2000) 7786.

[17] B. A. Hess, Phys. Rev. A 32 (1985) 756.

[18] J. C. Boettger, Phys. Rev. B 62 (2000) 7809. 
[19] T. Noro, M. Sekiya, T. Koga, Theoret. Chem. Acc. 131 (2012) 1124.

[20] T. H. Dunning, Jr. J. Chem. Phys. 90 (1989) 1007.

[21] C. Adamo, V. Barone, J. Chem. Phys. 110 (1999) 6158.

[22] J. Kästner, J. M. Carr, T. W. Keal, W. Thiel, A. Wander, P. Sherwood, J. Phys. Chem. A 113 (2009) 11856.

[23] M. E. Casida, in: D. P. Chong Ed., Recent Advances in Density Functional Methods, Part I, World Scientific, Singapore, 1995.

[24] U. C. Singh, P. A. Kollman, J. Comp. Chem. 5 (1984) 129.

[25] B. H. Besler, K. M. Merz Jr., P. A. Kollman, J. Comp. Chem. 11 (1990) 431.

[26] W. L. Jorgensen, D. S. Maxwell, J. Tirado-Rives, J. Am. Chem. Soc. 118 (1996) 11225.

[27] J. W. Ponder, Tinker Molecular Modeling Package, V5.1; Washington University Medical School: St. Louis, MO, 2010.

[28] Geometrical parameters of the dyes optimized by the scalar DFT with PBE1PBE were adopted and fixed in the MM calculations.

[29] E. M. J. Johansson, M. Odelius, S. Plogmaker, M. Gorgoi, S. Svensson, H. Siegbahn, H. Rensmo, J. Phys. Chem. C 114 (2010) 10314. 


\section{Figure captions}

FIGURE 1. Geometries of (a) Os-tbbpy and (b) Os-stbpy complexes

FIGURE 2. (a) Experimental and (b, c) simulated absorption spectra of Os-tbbpy and Os-stbpy calculated by $2 c-T D D F T / T D A$ calculations with and without the spin-orbit (SO) interaction. The methanol is used as a solvent. The peaks are illustrated by Lorentian-type functions with the half bandwidth of $0.8 \mathrm{eV}$.

FIGURE 3. Simulated absorption spectra of (a) Os-tbbpy and Os-stbpy, (b) Ru-tbbpy and Ru-stbpy, and (c) Os-stbpy-ext1 and Os-stbpy-ext2 calculated by 2c-TDDFT/TDA calculations with and without the spin-orbit (SO) interaction. The peaks are illustrated by Lorentian-type functions with the half bandwidth of $0.8 \mathrm{eV}$.

FIGURE 4. Geometries of (a) Os-stbpy-ext1 and (b) Os-stbpy-ext2 complexes 
(a)

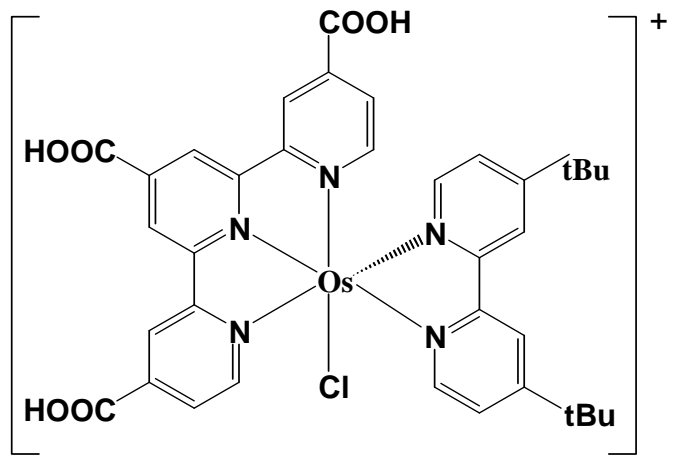

(b)

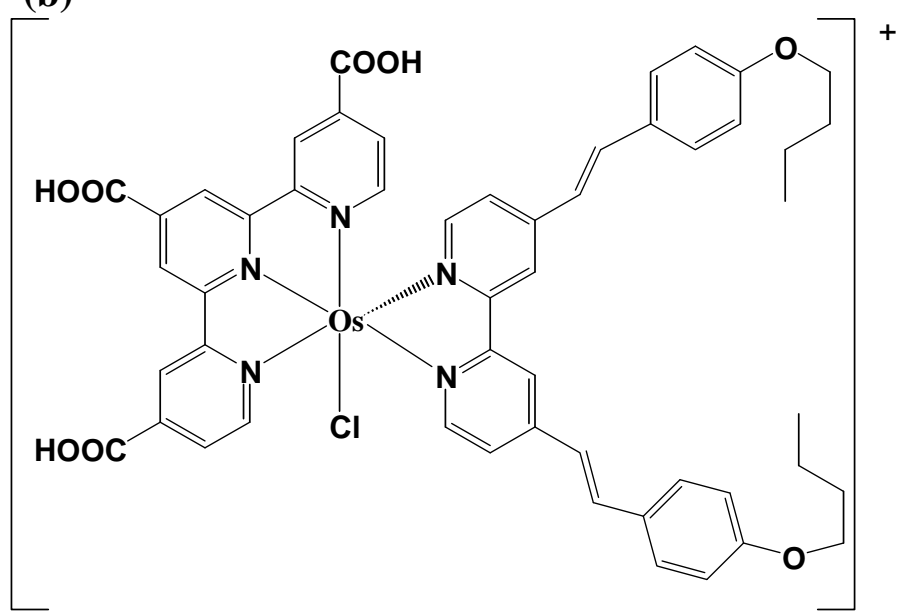

Figure 1 Imamura et al 
(a)

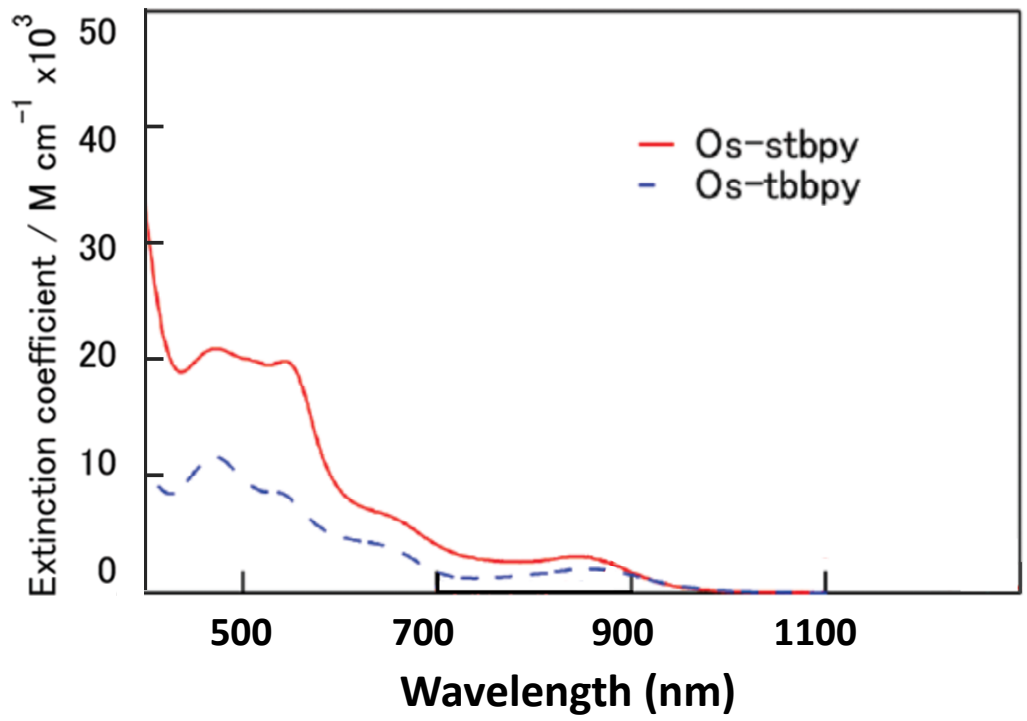

(b)

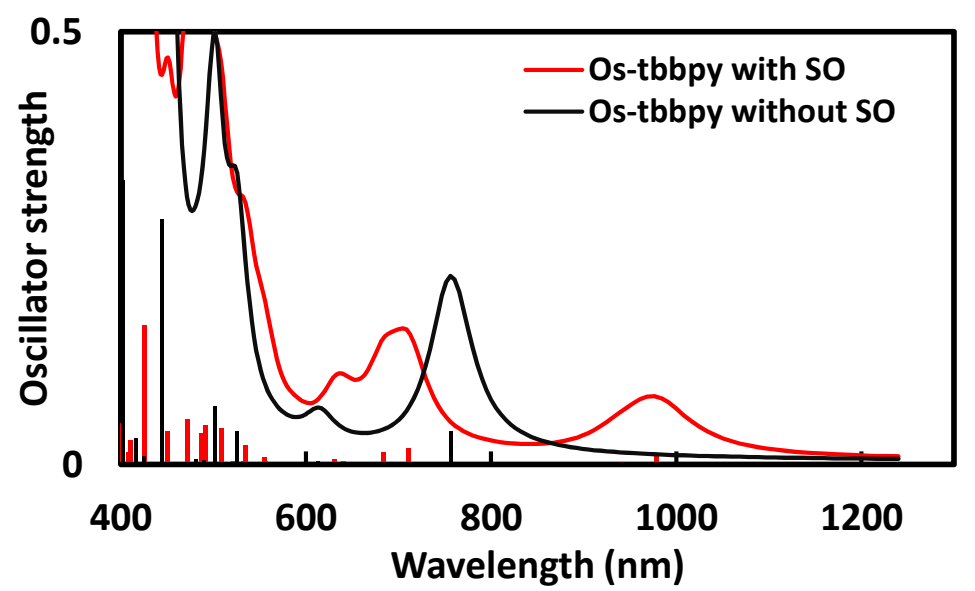

(c)

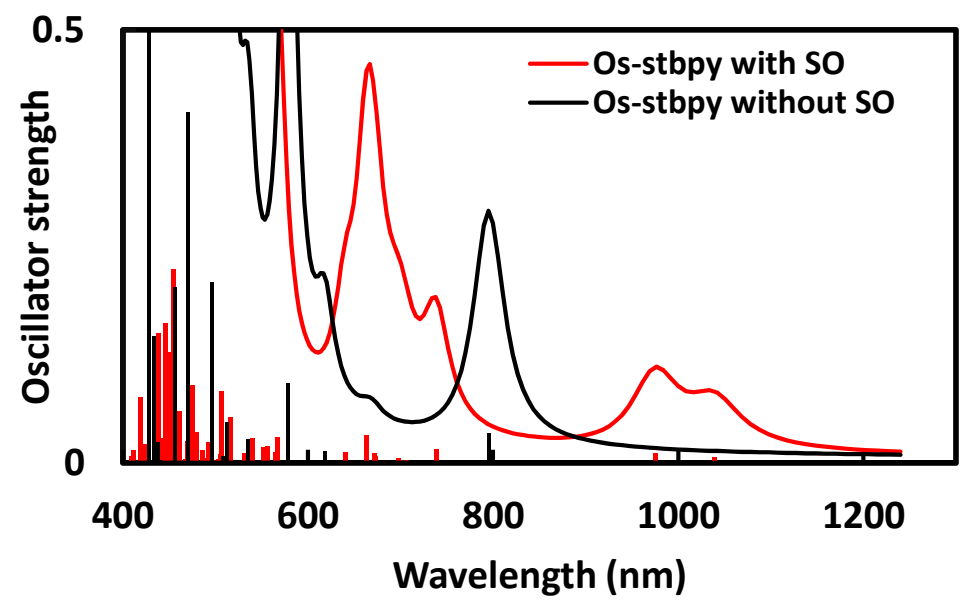

Figure 2 Imamura et al 
(a)

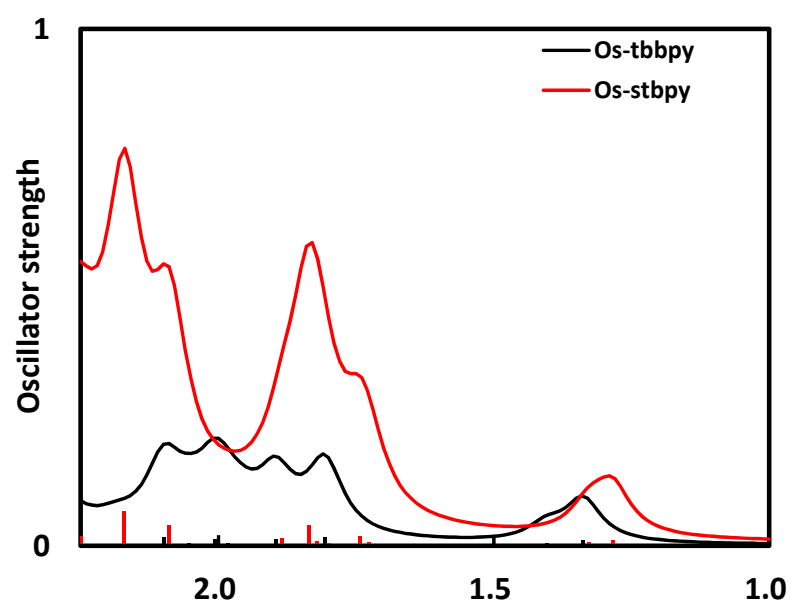

(b)

Excitation energy (eV)

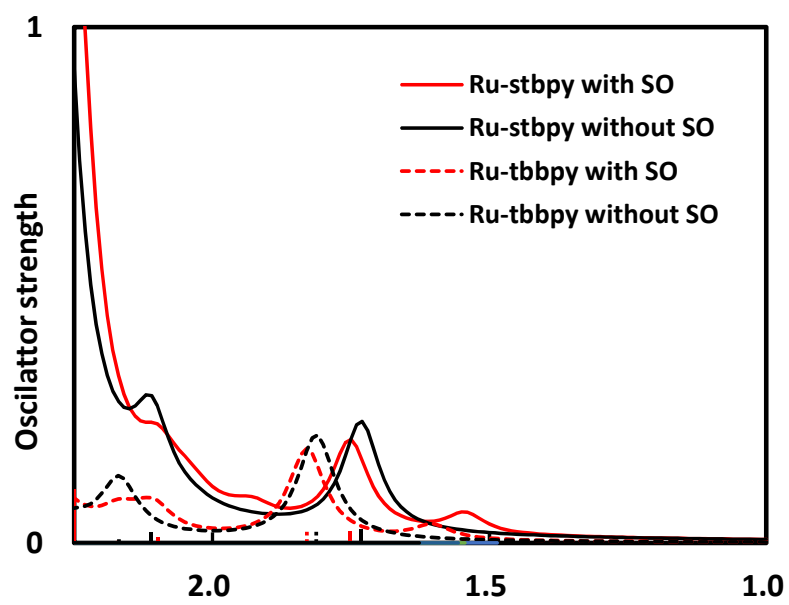

(c) Excitation energy (eV)

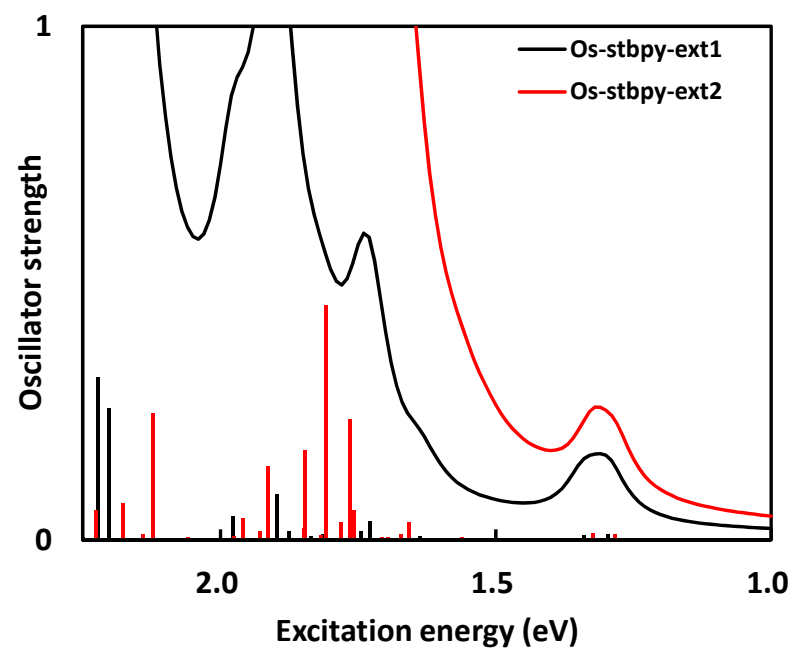

Figure 3 Imamura et al 


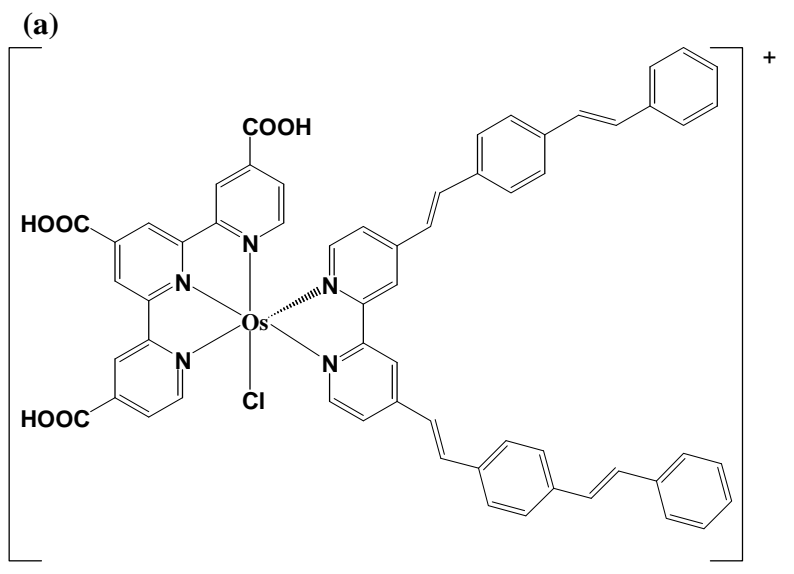

(b)

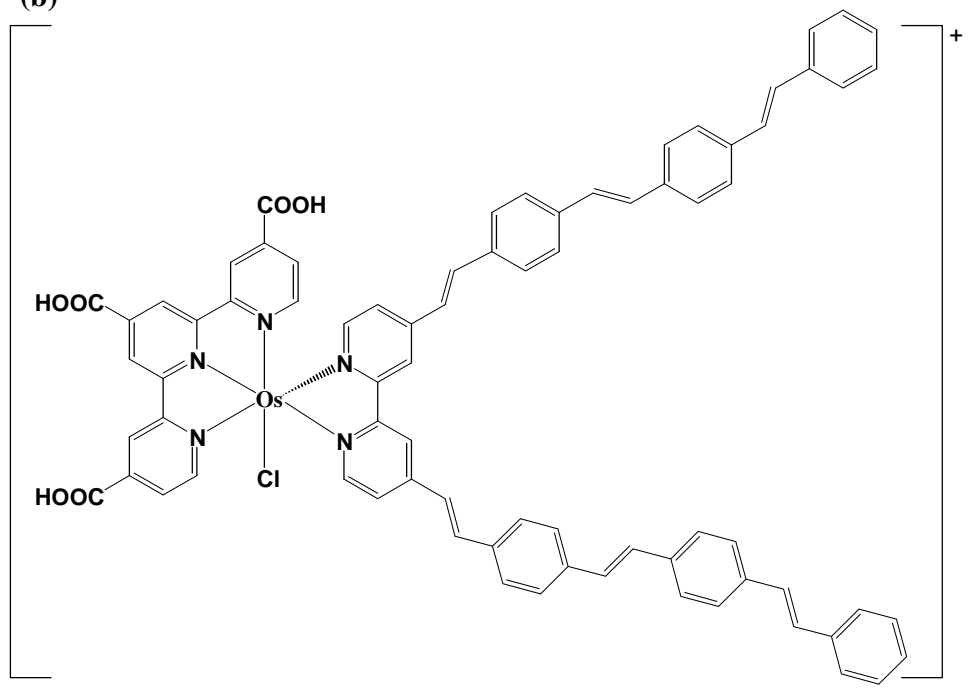

Figure 4 Imamura et al 
Table 1 Orbital energies for Os-tbbpy and Os-stbpy by 2c-relativistic DFT with and without the spin-orbit interaction.

\begin{tabular}{|c|c|c|c|c|c|c|c|}
\hline \multirow[t]{2}{*}{ Molecular orbital } & \multirow[t]{2}{*}{ Type } & \multicolumn{3}{|c|}{ Os tbbpy } & \multicolumn{3}{|c|}{ Os stbpy } \\
\hline & & $\mathrm{W} / \mathrm{O} \mathrm{SO}$ & $\mathrm{W} / \mathrm{SO}$ & $\Delta E$ & W/O SO & $\mathrm{W} / \mathrm{SO}$ & $\Delta E$ \\
\hline HOMO-2 & $t_{2 g}$ & -7.17 & -7.29 & -0.12 & -6.36 & -6.52 & -0.16 \\
\hline HOMO-1 & $t_{2 g}$ & -6.85 & -6.97 & -0.12 & -6.34 & -6.35 & -0.01 \\
\hline HOMO & $\mathrm{t}_{2 \mathrm{~g}}$ & -6.65 & -6.50 & 0.14 & -6.01 & -5.90 & 0.11 \\
\hline LUMO & $\pi^{*}$ & -3.91 & -3.92 & -0.01 & -3.41 & -3.42 & -0.01 \\
\hline LUMO+1 & $\pi^{*}$ & -3.56 & -3.56 & 0.00 & -3.12 & -3.12 & 0.00 \\
\hline$\Delta E($ HOMO-LUMO) & & 2.74 & 2.59 & -0.15 & 2.60 & 2.48 & -0.12 \\
\hline
\end{tabular}


Table 2 Excitation energies (eV) and oscillator strengths of the Os-tbbpy and Os-stbpy complexes with methanols by 2c-TDDFT/TDA with and without spin-orbit interaction. $\mathrm{H}$ and L represent HOMO and LUMO.

\begin{tabular}{|c|c|c|c|c|c|c|c|c|c|}
\hline \multirow[b]{2}{*}{ System } & \multicolumn{5}{|c|}{ Without spin-orbit interaction } & \multicolumn{4}{|c|}{ With spin-orbit interaction } \\
\hline & $\Delta E(\mathrm{eV})$ & $(\mathrm{nm})$ & Spin symmetry & $f$ & Main configuration $^{\mathrm{a}}$ & $\Delta E(\mathrm{eV})$ & $(\mathrm{nm})$ & $f$ & Main configuration $^{\mathrm{a}}$ \\
\hline \multirow[t]{15}{*}{ Os-tbbpy } & 1.35 & 916.1 & Triplet & 0.0000 & $\mathrm{H}->\mathrm{L}$ & 1.17 & 1058.7 & 0.0000 & $\mathrm{H}->\mathrm{L}$ \\
\hline & 1.35 & 916.1 & Triplet & 0.0000 & $\mathrm{H}->\mathrm{L}$ & 1.18 & 1050.8 & 0.0001 & $\mathrm{H}->\mathrm{L}$ \\
\hline & 1.35 & 916.1 & Triplet & 0.0000 & $\mathrm{H}->\mathrm{L}$ & 1.27 & 978.2 & 0.0113 & $\mathrm{H}->\mathrm{L}$ \\
\hline & 1.40 & 885.1 & Triplet & 0.0000 & $\mathrm{H}-1->\mathrm{L}$ & 1.32 & 940.6 & 0.0030 & $\mathrm{H}->\mathrm{L}$ \\
\hline & 1.40 & 885.1 & Triplet & 0.0000 & H-1->L & 1.57 & 789.1 & 0.0000 & H-1->L \\
\hline & 1.40 & 885.1 & Triplet & 0.0000 & $\mathrm{H}-1->\mathrm{L}$ & 1.57 & 788.4 & 0.0000 & $\mathrm{H}-1->\mathrm{L}$ \\
\hline & 1.64 & 756.7 & Singlet & 0.0388 & $\mathrm{H}->\mathrm{L}$ & 1.74 & 711.1 & 0.0188 & $\mathrm{H}-1->\mathrm{L}$ \\
\hline & 1.82 & 680.2 & Triplet & 0.0000 & $\mathrm{H}-2->\mathrm{L}$ & 1.77 & 699.9 & 0.0001 & $\mathrm{H}->\mathrm{L}+1$ \\
\hline & 1.82 & 680.2 & Triplet & 0.0000 & $\mathrm{H}-2->\mathrm{L}$ & 1.78 & 698.3 & 0.0001 & $\mathrm{H}->\mathrm{L}+1$ \\
\hline & 1.82 & 680.2 & Triplet & 0.0000 & $\mathrm{H}-2->\mathrm{L}$ & 1.81 & 683.8 & 0.0138 & $\mathrm{H}->\mathrm{L}+1$ \\
\hline & 1.88 & 658.1 & Triplet & 0.0000 & $\mathrm{H}->\mathrm{L}+1$ & 1.89 & 657.5 & 0.0007 & $\mathrm{H}->\mathrm{L}+1, \mathrm{H}-2->\mathrm{L}$ \\
\hline & 1.88 & 658.1 & Triplet & 0.0000 & $\mathrm{H}->\mathrm{L}+1$ & 1.94 & 640.6 & 0.0040 & $\mathrm{H}-2->\mathrm{L}, \mathrm{H}->\mathrm{L}+1$ \\
\hline & 1.88 & 658.1 & Triplet & 0.0000 & $\mathrm{H}->\mathrm{L}+1$ & 1.94 & 638.7 & 0.0006 & $\mathrm{H}-2->\mathrm{L}$ \\
\hline & 2.01 & 618.4 & Singlet & 0.0020 & $\mathrm{H}-2->\mathrm{L}$ & 1.96 & 631.3 & 0.0064 & $\mathrm{H}-2->\mathrm{L}$ \\
\hline & 2.02 & 612.9 & Singlet & 0.0041 & $\mathrm{H}->\mathrm{L}+1, \mathrm{H}-1->\mathrm{L}$ & 2.10 & 589.4 & 0.0014 & $\mathrm{H}-2->\mathrm{L}$ \\
\hline \multirow[t]{11}{*}{ Os-stbpy } & 1.27 & 975.6 & Triplet & 0.0000 & $\mathrm{H}->\mathrm{L}$ & 1.11 & 1117.2 & 0.0000 & $\mathrm{H}->\mathrm{L}$ \\
\hline & 1.27 & 975.6 & Triplet & 0.0000 & $\mathrm{H}->\mathrm{L}$ & 1.12 & 1106.6 & 0.0001 & $\mathrm{H}->\mathrm{L}$ \\
\hline & 1.27 & 975.6 & Triplet & 0.0000 & $\mathrm{H}->\mathrm{L}$ & 1.19 & 1039.4 & 0.0066 & $\mathrm{H}->\mathrm{L}$ \\
\hline & 1.39 & 895.1 & Triplet & 0.0000 & $\mathrm{H}-1->\mathrm{L}$ & 1.27 & 975.3 & 0.0108 & $\mathrm{H}->\mathrm{L}$ \\
\hline & 1.39 & 895.1 & Triplet & 0.0000 & $\mathrm{H}-1->\mathrm{L}$ & 1.53 & 812.0 & 0.0000 & $\mathrm{H}-1->\mathrm{L}, \mathrm{H}-2->\mathrm{L}$ \\
\hline & 1.39 & 895.1 & Triplet & 0.0000 & $\mathrm{H}-1->\mathrm{L}$ & 1.53 & 811.0 & 0.0000 & $\mathrm{H}-1->\mathrm{L}, \mathrm{H}-2->\mathrm{L}$ \\
\hline & 1.56 & 795.1 & Singlet & 0.0340 & $\mathrm{H}->\mathrm{L}$ & 1.68 & 738.3 & 0.0161 & $\mathrm{H}-2->\mathrm{L}, \mathrm{H}-1->\mathrm{L}$ \\
\hline & 1.68 & 738.0 & Triplet & 0.0000 & $\mathrm{H}-2->\mathrm{L}$ & 1.75 & 710.1 & 0.0001 & $\mathrm{H}->\mathrm{L}+1$ \\
\hline & 1.68 & 738.0 & Triplet & 0.0000 & $\mathrm{H}-2->\mathrm{L}, \mathrm{H}-4->\mathrm{L}$ & 1.76 & 705.9 & 0.0031 & $\mathrm{H}->\mathrm{L}+1, \mathrm{H}->\mathrm{L}+2$ \\
\hline & 1.68 & 738.0 & Triplet & 0.0000 & $\mathrm{H}-2->\mathrm{L}$ & 1.77 & 700.1 & 0.0033 & $\mathrm{H}->\mathrm{L}+1$ \\
\hline & 1.86 & 668.0 & Singlet & 0.0024 & $\mathrm{H}-2->\mathrm{L}$ & 1.78 & 697.4 & 0.0060 & H-1->L \\
\hline
\end{tabular}


$1.86 \quad 667.2 \quad$ Triplet

$1.86 \quad 667.2$ Triplet

$1.86 \quad 667.2$ Triplet

a $\mathrm{H}$ and $\mathrm{L}$ represent $\mathrm{HOMO}$ and LUMO.
$0.0000 \quad \mathrm{H}->\mathrm{L}+1, \mathrm{H}->\mathrm{L}+2$

$0.0000 \mathrm{H}->\mathrm{L}+1, \mathrm{H}->\mathrm{L}+2$

$0.0000 \quad \mathrm{H}->\mathrm{L}+1$ $\begin{array}{llll}1.80 & 689.3 & 0.0005 & \mathrm{H}->\mathrm{L}+2\end{array}$

$\begin{array}{llll}1.80 & 687.9 & 0.0014 & \mathrm{H}-2->\mathrm{L}\end{array}$

$\begin{array}{llll}1.81 & 684.0 & 0.0005 & \mathrm{H}->\mathrm{L}+2\end{array}$ 
Table 3 Excitation energies (eV) and oscillator strengths of the Os-tbbpy, Os-stbpy, Ru-tbbpy, Ru-stbpy, Os-stbpy-ext1, and Os-stbpy-ext2 complexes by 2c-TDDFT/TDA with and without spin-orbit interaction.

\begin{tabular}{|c|c|c|c|c|c|c|c|c|c|c|c|c|c|c|c|c|c|c|}
\hline \multicolumn{4}{|c|}{ Os-tbbpy } & \multicolumn{3}{|c|}{ Os-stbpy } & \multicolumn{3}{|c|}{ Ru-tbbpy } & \multicolumn{3}{|c|}{ Ru-stbpy } & \multicolumn{3}{|c|}{ Os-stbpy-ext1 } & \multicolumn{3}{|r|}{ Os-stbpy-ext2 } \\
\hline & \multicolumn{2}{|l|}{$\Delta E$} & \multirow{2}{*}{$\begin{array}{c}\text { Main } \\
\text { configuration }^{\mathrm{a}}\end{array}$} & \multicolumn{2}{|l|}{$\Delta E$} & \multirow{2}{*}{$\begin{array}{c}\text { Main } \\
\text { onfiguration }\end{array}$} & \multicolumn{2}{|l|}{$\Delta E$} & \multirow{2}{*}{$\begin{array}{c}\text { Main } \\
\text { onfiguration }\end{array}$} & \multicolumn{2}{|l|}{$\Delta E$} & \multirow{2}{*}{$\begin{array}{c}\text { Main } \\
\text { configuration }^{\mathrm{a}}\end{array}$} & \multicolumn{2}{|l|}{$\Delta E$} & \multirow{2}{*}{$\begin{array}{l}\text { Main } \\
\text { ffiguration }^{\mathrm{a}}\end{array}$} & \multicolumn{2}{|l|}{$\Delta E$} & \multirow{2}{*}{$\begin{array}{l}\text { Main } \\
\text { offiguration }^{\mathrm{a}}\end{array}$} \\
\hline & (eV) & $(\mathrm{nm})$ & & $(\mathrm{eV})$ & $(\mathrm{nm})$ & & $(\mathrm{eV})$ & $(\mathrm{nm})$ & & $(\mathrm{eV})$ & $(\mathrm{nm})$ & & $(\mathrm{eV})$ & $(\mathrm{nm})$ & & $(\mathrm{eV})$ & $(\mathrm{nm})$ & \\
\hline \multicolumn{19}{|c|}{ Without spin-orbit interaction } \\
\hline 1 & 1.44 & 860.1 & $0.0000 \mathrm{H}->\mathrm{L}$ & 1.37 & 905.0 & $0.0000 \mathrm{H}->\mathrm{L}, \mathrm{H}-3->\mathrm{L}$ & 1.63 & 762.2 & $0.0000 \mathrm{H}->\mathrm{L}$ & 1.54 & 803.0 & $0.0000 \mathrm{H}->\mathrm{L}, \mathrm{H}-3->\mathrm{L}$ & 1.38 & 898.4 & $0.0000 \mathrm{H}-2->\mathrm{L}, \mathrm{H}-1->\mathrm{L}$ & 1.37 & 907.1 & $0.0000 \mathrm{H}-2->\mathrm{L}, \mathrm{H}-5->\mathrm{L}, \mathrm{H}-1->\mathrm{L}$ \\
\hline 2 & 1.44 & 860.1 & $0.0000 \mathrm{H}->\mathrm{L}$ & 1.37 & 905.0 & $0.0000 \mathrm{H}->\mathrm{L}, \mathrm{H}-3->\mathrm{L}$ & 1.63 & 762.2 & $0.0000 \mathrm{H}->\mathrm{L}$ & 1.54 & 803.0 & $0.0000 \mathrm{H}->\mathrm{L}, \mathrm{H}-3->\mathrm{L}$ & 1.38 & 898.4 & $0.0000 \mathrm{H}-2->\mathrm{L}, \mathrm{H}-1->\mathrm{L}$ & 1.37 & 907.1 & $0.0000 \mathrm{H}-2->\mathrm{L}, \mathrm{H}-5->\mathrm{L}, \mathrm{H}-1->\mathrm{L}$ \\
\hline 3 & 1.44 & 860.1 & $0.0000 \mathrm{H}->\mathrm{L}$ & 1.37 & 905.0 & $0.0000 \mathrm{H}->\mathrm{L}$ & 1.63 & 762.2 & $0.0000 \mathrm{H}->\mathrm{L}$ & 1.54 & 803.0 & $0.0000 \mathrm{H}->\mathrm{L}, \mathrm{H}-3->\mathrm{L}$ & 1.38 & 898.4 & $0.0000 \mathrm{H}-2->\mathrm{L}, \mathrm{H}-1->\mathrm{L}$ & 1.37 & 907.1 & $0.0000 \mathrm{H}-2->\mathrm{L}$ \\
\hline 4 & 1.47 & 845.0 & $0.0000 \mathrm{H}-1->\mathrm{L}$ & 1.43 & 864.1 & $0.0000 \mathrm{H}-2->\mathrm{L}$ & 1.63 & 760.6 & $0.0000 \mathrm{H}-1->\mathrm{L}$ & 1.58 & 784.3 & $0.0000 \mathrm{H}-2->\mathrm{L}$ & 1.44 & 859.7 & $0.0000 \mathrm{H}-3->\mathrm{L}$ & 1.44 & 863.7 & $0.0000 \mathrm{H}-4->\mathrm{L}$ \\
\hline 5 & 1.47 & 845.0 & $0.0000 \mathrm{H}-1->\mathrm{L}$ & 1.43 & 864.1 & $0.0000 \mathrm{H}-2->\mathrm{L}$ & 1.63 & 760.6 & $0.0000 \mathrm{H}-1->\mathrm{L}$ & 1.58 & 784.3 & $0.0000 \mathrm{H}-2->\mathrm{L}$ & 1.44 & 859.7 & $0.0000 \mathrm{H}-3->\mathrm{L}$ & 1.44 & 863.7 & $0.0000 \mathrm{H}-4->\mathrm{L}$ \\
\hline 6 & 1.47 & 845.0 & $0.0000 \mathrm{H}-1->\mathrm{L}$ & 1.43 & 864.1 & $0.0000 \mathrm{H}-2->\mathrm{L}$ & 1.63 & 760.6 & $0.0000 \mathrm{H}-1->\mathrm{L}$ & 1.58 & 784.3 & $0.0000 \mathrm{H}-2->\mathrm{L}$ & 1.44 & 859.7 & $0.0000 \mathrm{H}-3->\mathrm{L}$ & 1.44 & 863.7 & $0.0000 \mathrm{H}-4->\mathrm{L}$ \\
\hline 7 & 1.71 & 727.2 & $0.0349 \mathrm{H}->\mathrm{L}$ & 1.64 & 757.4 & $0.0365 \mathrm{H}->\mathrm{L}$ & 1.81 & 684.1 & $0.0256 \mathrm{H}->\mathrm{L}$ & 1.73 & 715.9 & $0.0266 \mathrm{H}->\mathrm{L}$ & 1.64 & 755.5 & $0.0359 \mathrm{H}-2->\mathrm{L}, \mathrm{H}-1->\mathrm{L}$ & 1.53 & 811.2 & $0.0000 \mathrm{H}-1->\mathrm{L}+1$ \\
\hline 8 & 1.92 & 646.0 & $0.0000 \mathrm{H}-2->\mathrm{L}$ & 1.73 & 714.9 & $0.0000 \mathrm{H}-1->\mathrm{L}, \mathrm{H}-4->\mathrm{L}$ & 2.11 & 587.2 & $0.0000 \mathrm{H}-2->\mathrm{L}$ & 1.92 & 646.7 & $0.0000 \mathrm{H}-1->\mathrm{L}, \mathrm{H}-4->\mathrm{L}$ & 1.67 & 740.8 & $0.0000 \mathrm{H}-1->\mathrm{L}+1$ & 1.53 & 811.2 & $0.0000 \mathrm{H}-1->\mathrm{L}+1, \mathrm{H}-2->\mathrm{L}+1, \mathrm{H}-1->\mathrm{L}+3$ \\
\hline 9 & 1.92 & 646.0 & $0.0000 \mathrm{H}-2->\mathrm{L}$ & 1.73 & 714.9 & $0.0000 \mathrm{H}-1->\mathrm{L}, \mathrm{H}-4->\mathrm{L}$ & 2.11 & 587.2 & $0.0000 \mathrm{H}-2->\mathrm{L}$ & 1.92 & 646.7 & $0.0000 \mathrm{H}-1->\mathrm{L}, \mathrm{H}-4->\mathrm{L}$ & 1.67 & 740.8 & $0.0000 \mathrm{H}-1->\mathrm{L}+1, \mathrm{H}->\mathrm{L}+1$ & 1.53 & 811.2 & $0.0000 \mathrm{H}-1->\mathrm{L}+1, \mathrm{H}-2->\mathrm{L}+1, \mathrm{H}-1->\mathrm{L}+3$ \\
\hline 10 & 1.92 & 646.0 & $0.0000 \mathrm{H}-2->\mathrm{L}$ & 1.73 & 714.9 & $0.0000 \mathrm{H}-1->\mathrm{L}, \mathrm{H}-4->\mathrm{L}$ & 2.11 & 587.2 & $0.0000 \mathrm{H}-2->\mathrm{L}$ & 1.92 & 646.7 & $0.0000 \mathrm{H}-1->\mathrm{L}, \mathrm{H}-4->\mathrm{L}$ & 1.67 & 740.8 & $0.0000 \mathrm{H}-1->\mathrm{L}+1$ & 1.61 & 771.3 & $0.0307 \mathrm{H}-2->\mathrm{L}$ \\
\hline \multicolumn{19}{|c|}{ With spin-orbit interaction } \\
\hline 1 & 1.25 & 990.8 & $0.0000 \mathrm{H}->\mathrm{L}$ & 1.19 & 1042.5 & $0.0000 \mathrm{H}->\mathrm{L}$ & 1.56 & 796.9 & $0.0000 \mathrm{H}->\mathrm{L}$ & 1.49 & 834.4 & $0.0000 \mathrm{H}->\mathrm{L}, \mathrm{H}-2->\mathrm{L}$ & 1.20 & 1031.0 & $0.0000 \mathrm{H}-2->\mathrm{L}, \mathrm{H}->\mathrm{L}$ & 1.19 & 1040.6 & $0.0000 \mathrm{H}-2->\mathrm{L}$ \\
\hline 2 & 1.26 & 984.4 & $0.0001 \mathrm{H}->\mathrm{L}$ & 1.20 & 1033.4 & $0.0001 \mathrm{H}->\mathrm{L}$ & 1.56 & 796.1 & $0.0000 \mathrm{H}->\mathrm{L}$ & 1.49 & 833.2 & $0.0000 \mathrm{H}->\mathrm{L}, \mathrm{H}-2->\mathrm{L}$ & 1.21 & 1022.3 & $0.0001 \mathrm{H}-2->\mathrm{L}, \mathrm{H}->\mathrm{L}$ & 1.20 & 1031.3 & $0.0001 \mathrm{H}-2->\mathrm{L}$ \\
\hline 3 & 1.34 & 926.8 & $0.0104 \mathrm{H}->\mathrm{L}$ & 1.28 & 965.6 & $0.0114 \mathrm{H}->\mathrm{L}$ & 1.60 & 774.5 & $0.0030 \mathrm{H}-1->\mathrm{L}, \mathrm{H}->\mathrm{L}$ & 1.53 & 808.1 & $0.0011 \mathrm{H}->\mathrm{L}$ & 1.30 & 956.8 & $0.0114 \mathrm{H}-2->\mathrm{L}, \mathrm{H}->\mathrm{L}$ & 1.28 & 965.5 & $0.0113 \mathrm{H}-2->\mathrm{L}$ \\
\hline 4 & 1.40 & 882.9 & $0.0038 \mathrm{H}->\mathrm{L}$ & 1.33 & 934.5 & $0.0067 \mathrm{H}->\mathrm{L}$ & 1.62 & 766.1 & $0.0006 \mathrm{H}->\mathrm{L}$ & 1.55 & 801.8 & $0.0039 \mathrm{H}-2->\mathrm{L}, \mathrm{H}->\mathrm{L}$ & 1.34 & 925.8 & $0.0097 \mathrm{H}->\mathrm{L}, \mathrm{H}-2->\mathrm{L}$ & 1.32 & 936.7 & $0.0135 \mathrm{H}-2->\mathrm{L}$ \\
\hline 5 & 1.65 & 752.0 & $0.0000 \mathrm{H}-1->\mathrm{L}$ & 1.59 & 778.4 & $0.0000 \mathrm{H}-1->\mathrm{L}, \mathrm{H}-2->\mathrm{L}$ & 1.69 & 732.4 & $0.0000 \mathrm{H}-1->\mathrm{L}$ & 1.63 & 761.3 & $0.0000 \mathrm{H}-2->\mathrm{L}, \mathrm{H}-3->\mathrm{L}$ & 1.60 & 775.6 & $0.0000 \mathrm{H}-4->\mathrm{L}$ & 1.51 & 821.5 & $0.0000 \mathrm{H}-1->\mathrm{L}+1$ \\
\hline 6 & 1.65 & 751.4 & $0.0000 \mathrm{H}-1->\mathrm{L}$ & 1.59 & 777.5 & $0.0000 \mathrm{H}-1->\mathrm{L}, \mathrm{H}-2->\mathrm{L}$ & 1.69 & 732.3 & $0.0000 \mathrm{H}-1->\mathrm{L}$ & 1.63 & 761.2 & $0.0000 \mathrm{H}-2>>\mathrm{L}, \mathrm{H}-3->\mathrm{L}$ & 1.61 & 772.4 & $0.0001 \mathrm{H}-4>\mathrm{L}$ & 1.51 & 820.7 & $0.0000 \mathrm{H}-1->\mathrm{L}+1$ \\
\hline 7 & 1.81 & 686.4 & $0.0175 \mathrm{H}-1->\mathrm{L}$ & 1.70 & 731.5 & $0.0002 \mathrm{H}->\mathrm{L}+1$ & 1.83 & 677.7 & 0.0219 H-1->L, H->L & 1.75 & 707.9 & $0.0216 \mathrm{H}->\mathrm{L}, \mathrm{H}-3->\mathrm{L}$ & 1.61 & 769.2 & $0.0001 \mathrm{H}->\mathrm{L}+1$ & 1.52 & 816.5 & $0.0020 \mathrm{H}-1->\mathrm{L}+1$ \\
\hline 8 & 1.85 & 669.2 & $0.0000 \mathrm{H}->\mathrm{L}+1$ & 1.70 & 729.5 & $0.0000 \mathrm{H}->\mathrm{L}+1$ & 2.10 & 590.4 & $0.0013 \mathrm{H}->\mathrm{L}+1$ & 1.92 & 644.9 & $0.0023 \mathrm{H}-1->\mathrm{L}, \mathrm{H}-4->\mathrm{L}$ & 1.62 & 765.8 & $0.0000 \mathrm{H}->\mathrm{L}+1, \mathrm{H}-4>\mathrm{L}$ & 1.56 & 793.9 & $0.0041 \mathrm{H}->\mathrm{L}+1$ \\
\hline 9 & 1.86 & 667.0 & $0.0004 \mathrm{H}->\mathrm{L}+1$ & 1.73 & 717.9 & $0.0069 \mathrm{H}->\mathrm{L}+1$ & 2.10 & 589.9 & $0.0000 \mathrm{H}->\mathrm{L}+1$ & 1.93 & 642.1 & $0.0000 \mathrm{H}-1->\mathrm{L}, \mathrm{H}-4->\mathrm{L}$ & 1.64 & 757.1 & $0.0069 \mathrm{H}->\mathrm{L}+1, \mathrm{H}-1->\mathrm{L}+1$ & 1.57 & 790.8 & $0.0001 \mathrm{H}->\mathrm{L}+1$ \\
\hline 10 & 1.90 & 653.9 & $0.0133 \mathrm{H}->\mathrm{L}+1$ & 1.74 & 711.7 & $0.0182 \mathrm{H}-2->\mathrm{L}, \mathrm{H}-3->\mathrm{L}$ & 2.11 & 588.7 & $0.0032 \mathrm{H}-2->\mathrm{L}, \mathrm{H}->\mathrm{L}+1$ & 1.93 & 641.0 & 0.0006 H-1 $>$ -, $\mathrm{H}-4->\mathrm{L}$ & 1.73 & 717.4 & $0.0364 \mathrm{H}->\mathrm{L}+1$ & 1.57 & 790.3 & $0.0001 \mathrm{H}->\mathrm{L}+1$ \\
\hline
\end{tabular}

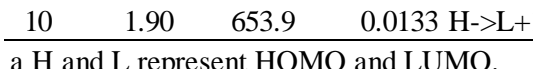




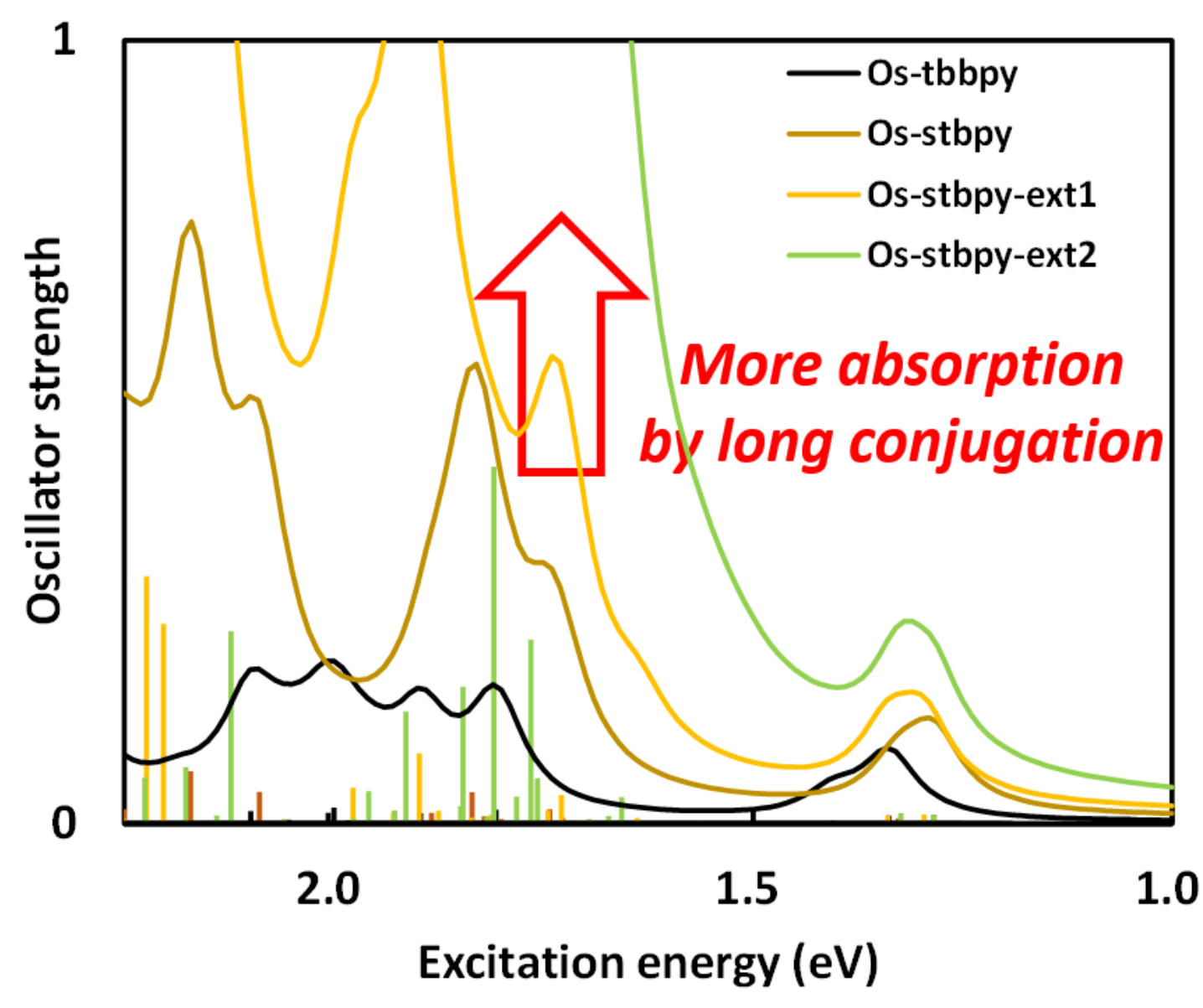

\section{Os complex}

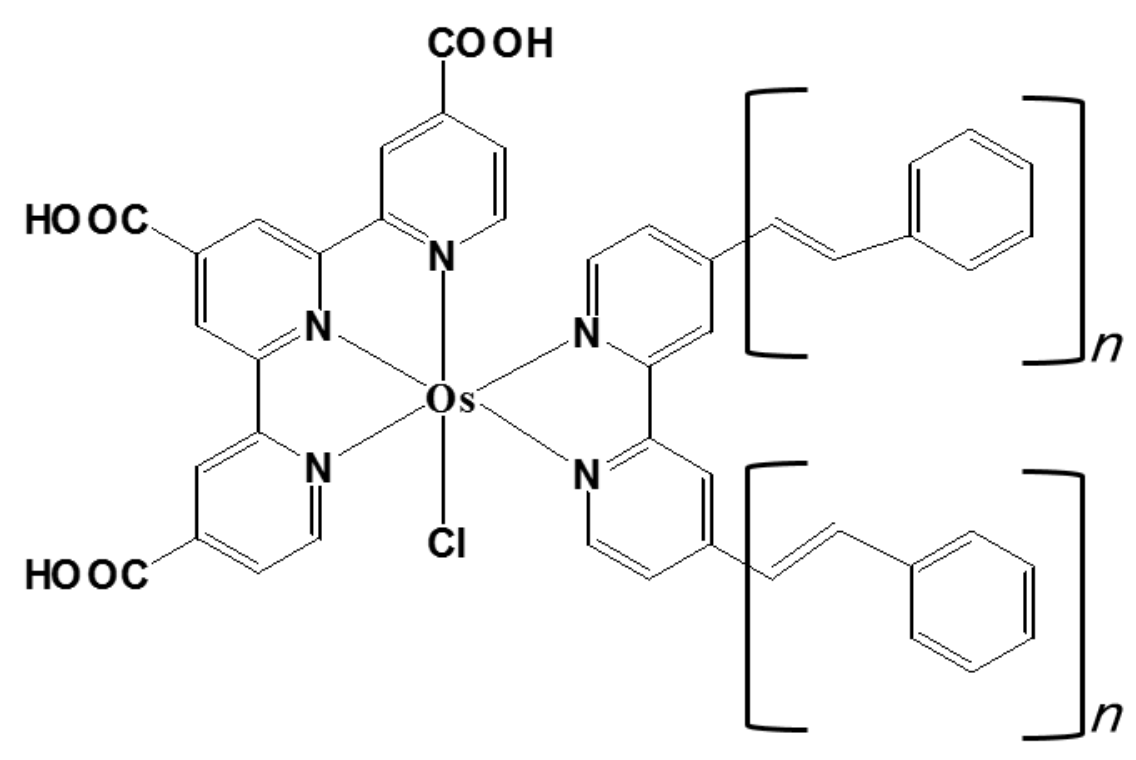

